Life Sciences Division

\title{
TREATMENT OF MERCURY CONTAMINATED OIL FROM SANDIA NATIONAL LABORATORY
}

\author{
K. T. Klasson
}

\section{Topical Report}

Date Published-April 2002

"The submitted manuscript has been authored by a contractor of the U.S. Government under contract No. DE-AC05-00OR22725. Accordingly, the U.S. Government retains a nonexclusive, royalty-free license to publish or reproduce the published form of the contribution, or allow others to do so, for U.S. Government purposes."

Prepared by

OAK RIDGE NATIONAL LABORATORY

Oak Ridge, Tennessee 37831

managed by

UT-BATTELLE, LLC

for the

U.S. DEPARTMENT OF ENERGY

under contract DE-AC05-00OR22725 


\title{
Treatment of Mercury Contaminated Oil from Sandia National Laboratory
}

\author{
K. Thomas Klasson \\ Oak Ridge National Laboratory \\ Oak Ridge, Tennessee 37831-6226 \\ (865) 574-6813, klassonkt@ornl.gov
}

\section{Introduction}

First Article Tests of a stabilization method for greater than $260 \mathrm{mg}$ mercury $/ \mathrm{kg}$ oil were performed under a treatability study. This alternative treatment technology will address treatment of U.S. Department of Energy (DOE) organics (mainly used pump oil) contaminated with mercury and other heavy metals. Some of the oil is also co-contaminated with tritium, other radionuclides, and hazardous materials.

The technology is based on contacting the oil with a sorbent powder (Self-Assembled Mercaptan on Mesoporous Support, SAMMS), proven to adsorb heavy metals, followed by stabilization of the oil/powder mixture using a stabilization agent (Nochar N990). Two variations of the treatment technology were included in the treatability study.

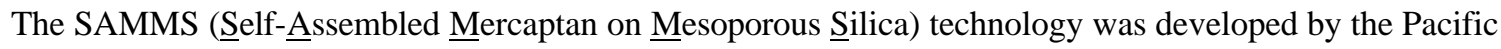
Northwest National Laboratory for removal and stabilization of RCRA metals (i.e., lead, mercury, cadmium, silver, etc.) and for removal of mercury from organic solvents [1]. The SAMMS material is based on self-assembly of functionalized monolayers on mesoporous oxide surfaces. The unique mesoporous oxide supports provide a high surface area, thereby enhancing the metal-loading capacity.

SAMMS material has high flexibility in that it binds with different forms of mercury, including metallic, inorganic, organic, charged, and neutral compounds [1] The material removes mercury from both organic wastes, such as pump oils, and from aqueous wastes. Mercury-loaded SAMMS not only passes TCLP tests, but also has good longterm durability as a waste form because: 1) the covalent binding between mercury and SAMMS has good resistance in ion-exchange, oxidation, and hydrolysis over a wide $\mathrm{pH}$ range and 2) the uniform and small pore size of the mesoporous silica prevents bacteria from solubilizing the bound mercury.

Nochar's N990 Petrobond (Nochar, Inc., Indianapolis, IN) is an oil stabilization agent, specifically formulated for stabilizing vacuum pump oil, which has fewer volatile organics than many other oils. This material is a non-uniform granular powder that resembles ground Styrofoam plastics. This material has previously been used by itself and in 
combination with SAMMS to stabilize oil containing low levels of mercury $\leq 50 \mathrm{mg} / \mathrm{kg}$ in surrogate waste studies [2].

\section{Materials and Methods}

Used vacuum pump oil was shipped from Sandia National Laboratory to Oak Ridge National Laboratory for First Article testing as part of a treatability study. Two containers were shipped to ORNL (Fig. 1). The first container held approximately $872 \mathrm{~g}$ of oil from pump number S554976 and based on the analytical data provided from SNL the waste oil contained $198 \mathrm{mg} / \mathrm{kg} \mathrm{Ba}, 6.5 \mathrm{mg} / \mathrm{kg} \mathrm{Cd}, 4 \mathrm{mg} / \mathrm{kg} \mathrm{Pb}, 0.5 \mathrm{mg} / \mathrm{kg} \mathrm{Ag}$, and $540 \mathrm{mg} / \mathrm{kg} \mathrm{Hg}$. The other container contained approximately $29 \mathrm{~g}$ of oil from pump number $3 \mathrm{~A}$ and based on the analytical data provided from SNL the waste oil contained $4.13 \mathrm{mg} / \mathrm{kg} \mathrm{Hg}$ and no other metals. The total tritium contained in the oil was $17 \mu \mathrm{Ci}$. The content from both containers were combined and mixed before use.

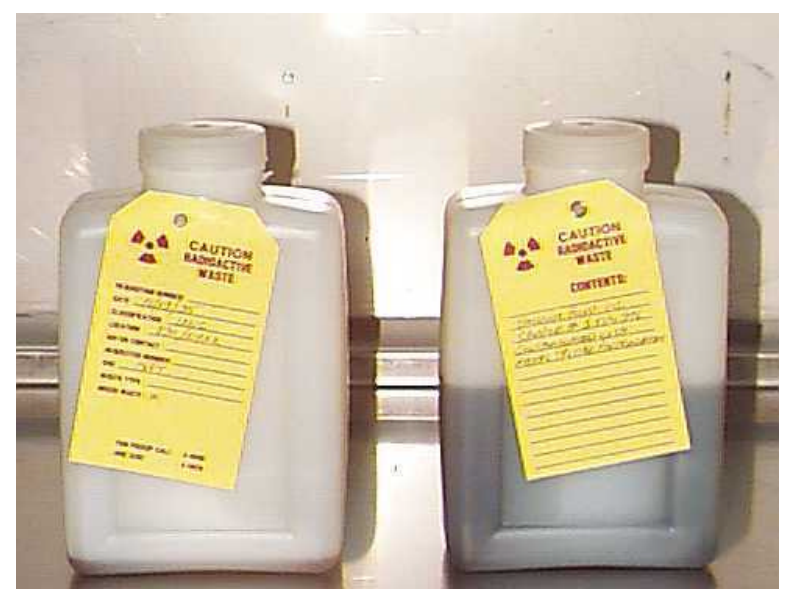

Fig. 1. Containers of oil shipped from SNL to ORNL.

The SAMMS material used in this study was received from PNNL as a fine white powder. This material is hydrophobic and mixes very well with oil. The N990 Petrobond material was received from Nochar, Inc., Indianapolis, IN. These materials were used in two approaches.

1. The first approach (Approach A) involved dry-mixing of SAMMS material and Nochar N990 (4\% SAMMS by weight) using equipment similar to a drum roller (Fig. 2). This mixture was placed in a container (1 liter glass container). The oil was then directly added to the container and allowed to be absorbed. Equal weight of oil and Nochar N990 was used. Four percent SAMMS was chosen because in past experiments oil poured on top of (equal weight) Nochar N990 penetrated half-way. Thus, all the oil would be in contact with approximately half of the SAMMS added to the container.

2. The second approach (Approach B) involved mixing of SAMMS and oil for $24 \mathrm{hr}$. The amount of SAMMS used was $2 \%(\mathrm{w} / \mathrm{w})$. After mixing, the mixture was poured over Nochar 990 (in 1-liter glass containers). Equal weight of Nochar and oil was used. 


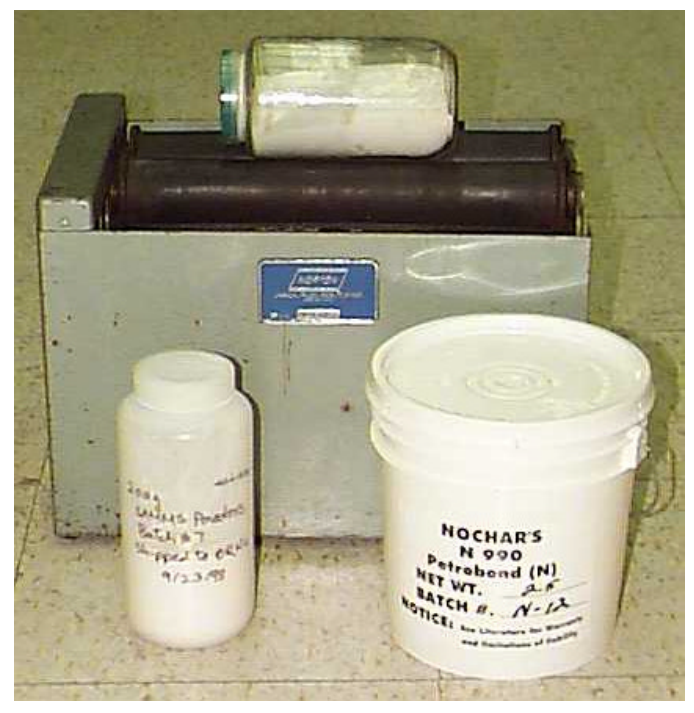

Fig. 2. "Drum roller" used to dry-mix SAMMS and Nochar's N990.

Triplicate treatment was performed using each method, treating approximately $150 \mathrm{~g}$ oil with 3 to $6 \mathrm{~g}$ of SAMMS and $150 \mathrm{~g} \mathrm{N990.} \mathrm{All} \mathrm{three} \mathrm{of} \mathrm{containers} \mathrm{with} \mathrm{the} \mathrm{solidified} \mathrm{oils} \mathrm{using} \mathrm{the} \mathrm{first} \mathrm{approach} \mathrm{were} \mathrm{samples} \mathrm{and} \mathrm{two} \mathrm{of} \mathrm{the}$ containers using the second approach were sampled according to a Sampling and Analysis Plan (attached).

\section{Results and Discussion}

Both of the two treatment approaches were easy to implement. Of the two methodologies, the first approach using a stabilization agent consisting of dry-mixed SAMMS and Nochar N990 would be easier to implement on a large scale. Some difficulty of mixing dry SAMMS and oil was noted requiring initial vigorous mixing to prevent the SAMMS from clumping together. On a large scale, this could be implemented with for example an impeller-type drum mixer if the treatment was performed in drums or as an alternative the SAMMS material could be presoaked in a solvent. The oil soaked quickly into the Nochar N990. After 30 minutes the oil was absorbed to a large extent (Fig. 3) and reached a constant penetration depth in a few hours. The penetration depth was deeper that expected, penetrating approximately $75 \%$ of the total height (Fig. 4). It had been expected that the oil would only penetrate to $50 \%$ of the total height. This means that, in the case of the first approach, the oil $(150 \mathrm{~g})$ was contacted with $4.5 \mathrm{~g}$ of SAMMS (present within the top (75\%) layer). The oil was contacted with $3 \mathrm{~g}$ of SAMMS in the second approach. 


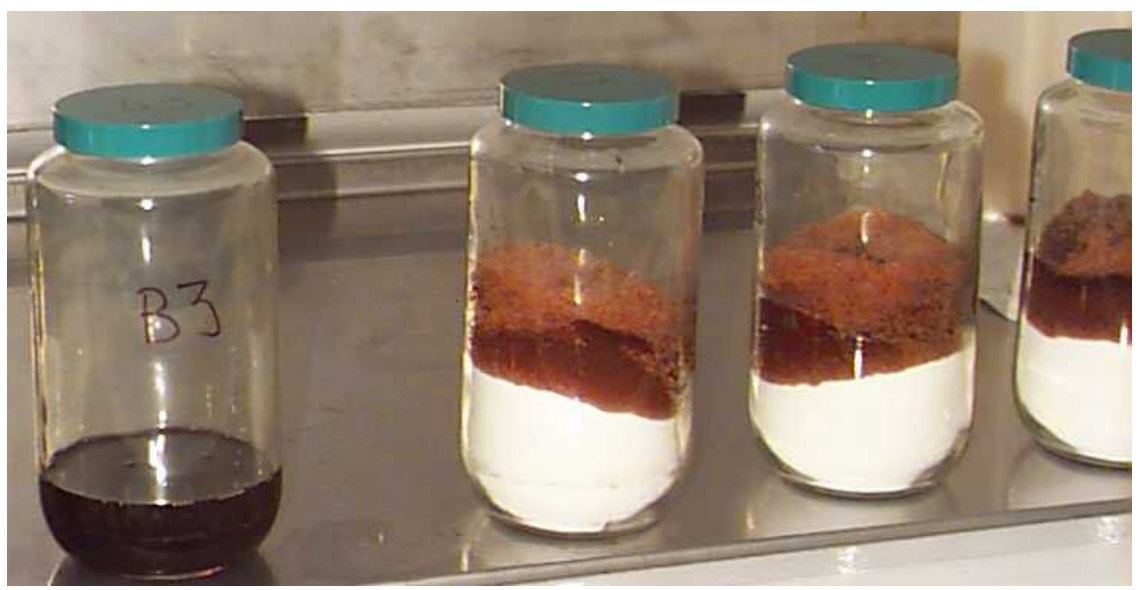

Fig. 3. Penetration depth after $30 \mathrm{~min}$ of oil into mixture of SAMMS and Nochar N990. The amount of oil $(150 \mathrm{~g})$ in each container is shown in the container labeled B3 to the left.

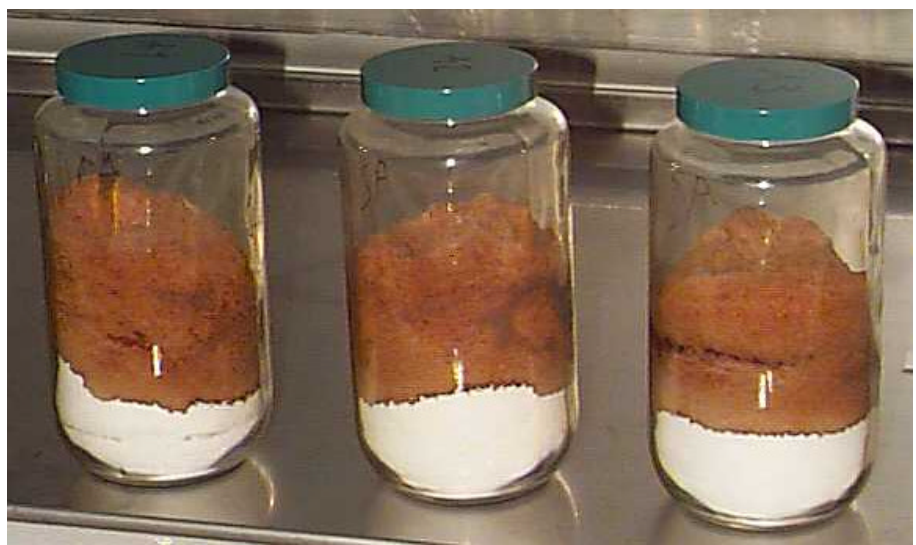

Fig. 4. Penetration depth after 24 hours of oil into mixtures of SAMMS and Nochar N990.

During the second approach, a slight variation of the planned activities were tested based on the following scenario:

With a large-scale treatment method one may envision that the waste is contained in drums. The method for treatment would be to add SAMMS material directly to the drum through the bung. Then, the content would be mixed with a drum mixer for $24 \mathrm{~h}$. The SAMMS/oil mixture would be pumped into a new drum ("a stabilization drum") containing Nochar N990. When the original drum was empty (some slight oil would remain in the heel) this drum may serve as the next stabilization drum receiving a charge of Nochar N990.

Thus, this variation was tried by mixing SAMMS and oil in a container, emptying this container, adding Nochar N990 to the container, and finally returning the SAMMS oil mixture to this container. When performed, this methodology was perceived not to work well because the oil penetrated via wall-channeling to the bottom of the 
container (compare Fig. 5 and Fig. 6). The Nochar finally soaked the oil and no free oil was visually noted in the bottom of the container, but from a visual standpoint the method looked less efficient.

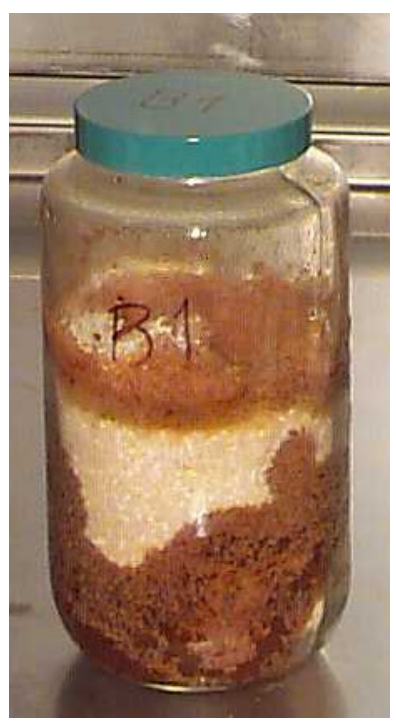

Fig. 5. Penetration of oil to the

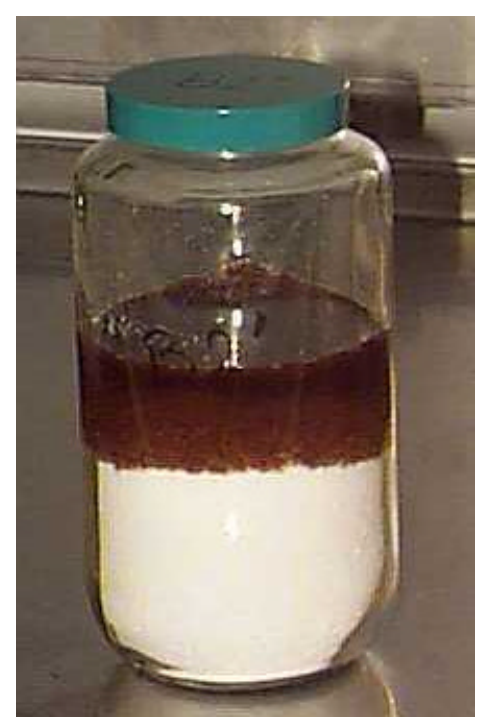

Fig. 6. Normal penetration profile. bottom of the container.

The sampling protocol called for removing the solidified oil by layer (4 layers per container), sampling each layer for total mercury and leachability (TCLP) of metals. Unused stabilization agent at the bottom of each container was not sampled. It should be noted that the stabilized matrix was sampled 2 months after the stabilization. The results from the analyses are shown in Fig. 7-9. 


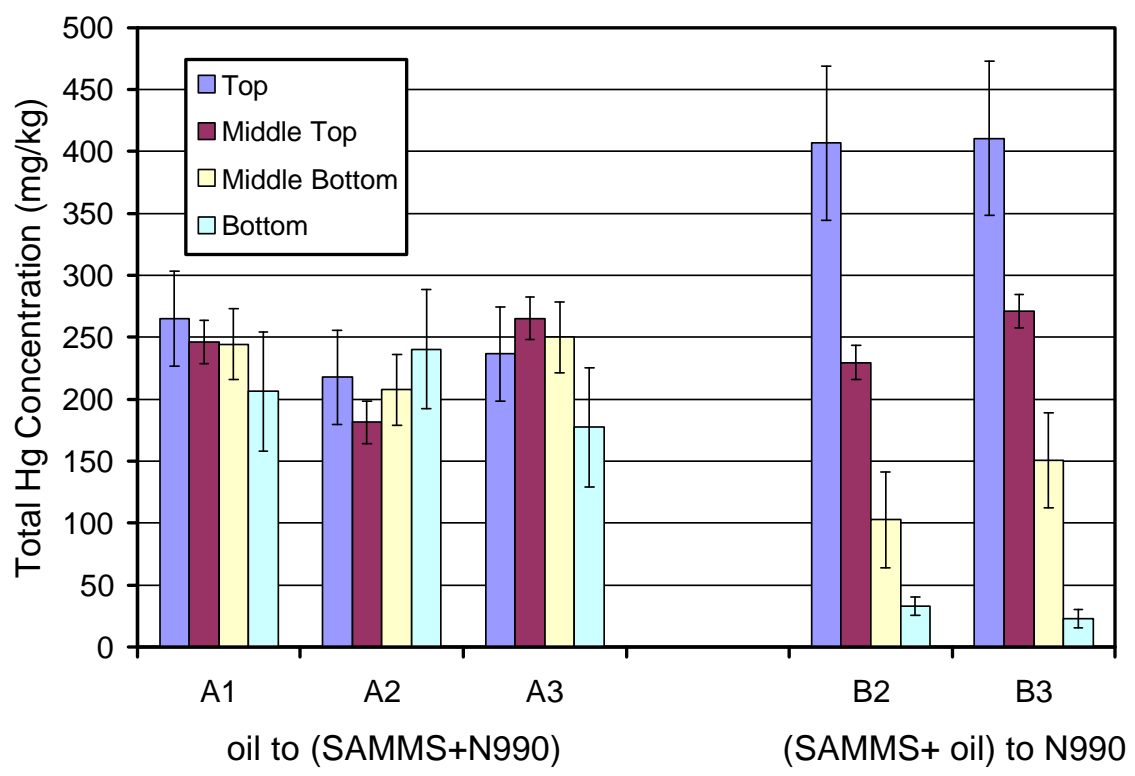

Fig. 7. Total concentration of mercury within each layer of the of the solidified oil matrix. For each layer, three samples were collected for total mercury analysis.

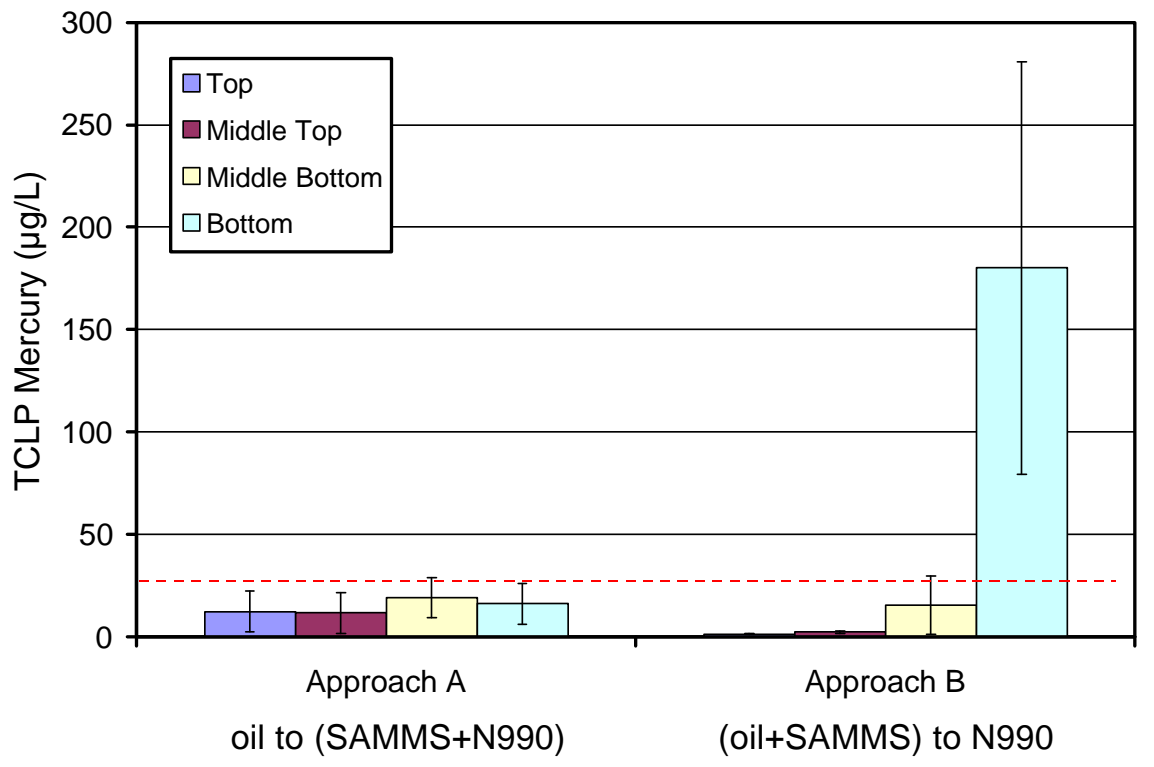

Fig. 8. Leachability of mercury in each layer of the solidified oil matrix. Dashed line indicates treatment goal. 


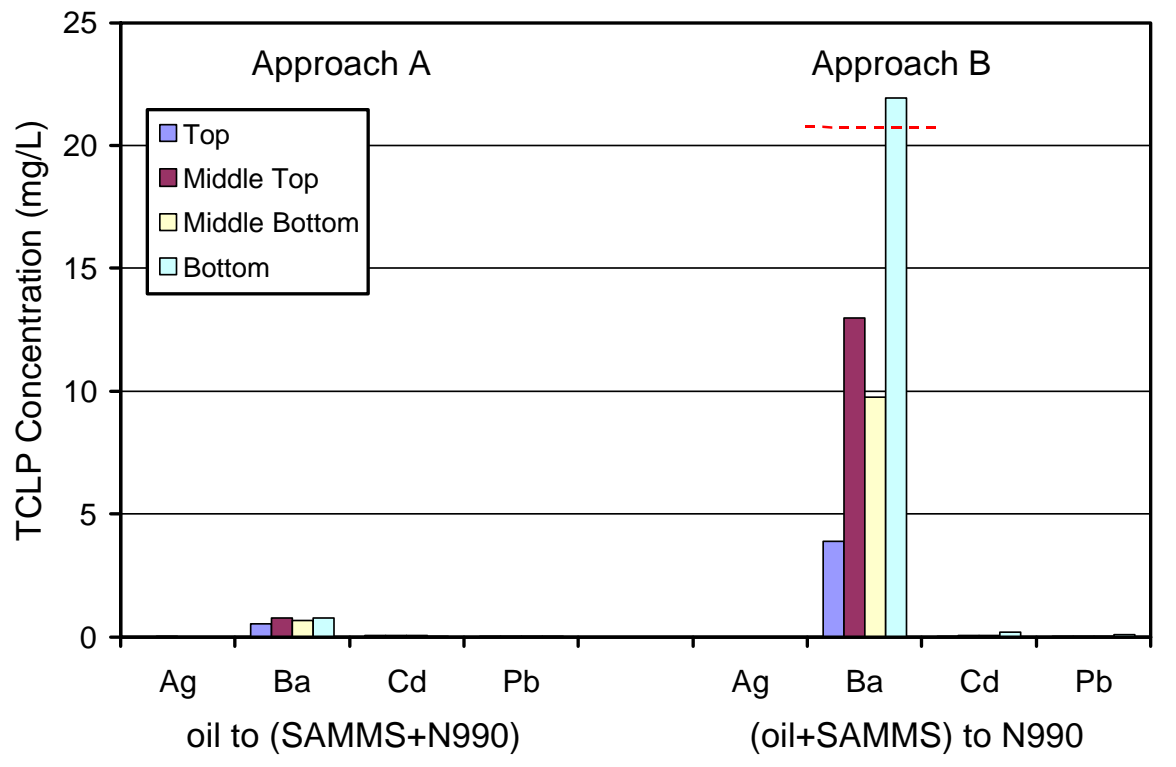

Fig. 9. Leachability of other RCRA metals in each layer of the solidified oil matrix. Dashed line indicates treatment goal for barium. The other metals were below the treatment goals for all other cases.

The total mercury concentration measurements in the solidified matrix in Approach A show that this waste form was uniform (Fig. 7). The leachability of mercury in the solidified matrix in Approach A was very low at less than 0.025 $\mathrm{mg} / \mathrm{L}$, the UTS limit (Fig. 8).

This was not the case in Approach B where the Nochar N990 acted as a porous bed, filtering the oil as it penetrated and capturing the mercury-laden SAMMS in the upper portion of the matrix. This resulted in a distribution of both total and leachable mercury along the depth of the solidified matrix (Fig. 7 and Fig. 8).

In the case of Approach B, the leachability of mercury from the matrix was higher from the bottom layer, but still very low at $0.18 \mathrm{mg} / \mathrm{L}$. We draw the following conclusions from the results:

1. In Approach B, the contaminated oil was only contacted with SAMMS for $24 \mathrm{~h}$, before stabilization. However, in Approach A, the contact time was two months after stabilization; as the oil, SAMMS, and Nochar N990 formed a uniform medium. Mercury not yet adsorbed to SAMMS could easily diffuse the anticipated short distance to a SAMMS particle. This was not the case in Approach B as the SAMMS was captured in the upper portion of the matrix, leaving unadsorbed mercury in the lower portion of the bed. The distance for this mercury to a SAMMS particle was too great for diffusion. In the past we have shown that prolonged contact time improves removal efficiency [3]; $24 \mathrm{~h}$ was selected to anticipate a typical work schedule on a large-scale implementation. In retrospect, we should have allowed equal contact times for both approaches.

2. Nochar N990 should have stabilized the oil (and mercury) that penetrated the bed in Approach B. By design, the amount of SAMMS added to the oil would reduce the mercury level by about 90\%; Nochar N990 would 
stabilize the remainder. As Nochar N990 has successfully been used to stabilize oil with $50 \mathrm{mg}$ mercury/kg, we targeted this concentration by adding enough SAMMS (but not more) to reach this level after $24 \mathrm{~h}$ contact time. Even though the performance of the SAMMS material by itself was not measured directly, we can calculate from the data presented in Fig. 7 that the oil after being contacted with SAMMS contained approximately 46 $\mathrm{mg} \mathrm{Hg} / \mathrm{kg}$ oil [4], which is within range of the planned value. Based on previous results [2], Nochar N990 should have stabilized this mercury to pass UTS limit. Low leachability $(0.18 \mathrm{mg} / \mathrm{L})$ was achieved in Approach B, but not low enough for Land Disposal Restrictions. We speculate the limitation of Nochar N990 to stabilize the mercury was due to difference in mercury speciation in our current experiment and the standards used to spike oil in surrogate studies at $50 \mathrm{mg} / \mathrm{L} \mathrm{[2].} \mathrm{This} \mathrm{finding} \mathrm{would} \mathrm{suggest} \mathrm{the} \mathrm{importance} \mathrm{to} \mathrm{either} \mathrm{analyze} \mathrm{for}$ the various mercury species (which is not trivial) or implementing a simple test protocol to demonstrate the effectiveness of the stabilization for each new waste stream.

3. Above, we discussed the limitation of Nochar N990 not to "completely" stabilize the mercury in the oil. The fact is that the Nochar N990 did very well. The matrix in the bottom layer of stabilized oil contained $28 \mathrm{mg}$ $\mathrm{Hg} / \mathrm{kg}$ matrix (Fig. 7). When submitted to the leaching procedure only a fraction $(3.6 \mathrm{mg} / \mathrm{kg})$ leached out, resulting in $0.18 \mathrm{mg} / \mathrm{L}$ in the leaching liquid. It is very possible that this is the same fraction that during long contact times with SAMMS in Approach A could be stabilized by SAMMS. This again suggests the importance of initial testing before final stabilization methodology is employed.

\section{Conclusions}

The results demonstrate that a stabilization agent containing SAMMS (4\%) and Nochar N990 can stabilize the oil containing heavy metals at substantial concentrations. The stabilized oil meets Land Disposal Restrictions for leachability of metals. The combination of SAMMS and Nochar N990 as a stabilization matrix is advantageous and the technology would be easily implemented on a larger scale with stabilization drums containing mixture of SAMMS and Nochar N990. Oil can be added to this container periodically until the full capacity is utilized.

\section{References}

1. Feng, X., J. Liu, G.E. Fryxell, M. Gong, L.-Q. Wang, X. Chen, D.E. Kurath, C.S. Ghormley, K.T. Klasson, and K.M. Kemner, "Self-Assembled Mercaptan on Mesoporous Silica (SAMMS) Technology for Mercury Removal and Stabilization," Pacific Northwest National Laboratory, PNNL-11691, (September 1997).

2. Klasson, K.T., "Treatment of Mercury Contaminated Oil from the Mound Site," Oak Ridge National Laboratory, Report number R00-109113, (November 2000).

3. Klasson, K.T., P.A. Taylor, R.L. Cummins, and B.S. Evans, "Removal of Mercury and Tritium from DOE Waste Oils," Oak Ridge National Laboratory, ORNL/TM-13751, (March 1999).

4. In the two bottles used for Approach B, approximately $3.5 \mathrm{~cm}$ of unused Nochar remained in the bottle. The initial height, corresponding to $150 \mathrm{~g}$, was $10 \mathrm{~cm}$. Thus, $97.5 \mathrm{~g}$ of Nochar $(=150 \times 6.5 \div 10)$ absorbed $150 \mathrm{~g}$ oil. The average total mercury concentration in the bottom layer in Approach B was $28 \mathrm{~g} / \mathrm{kg}$ solidified oil (Fig. 7). This value can be used to back-calculate the mercury concentration in the oil as $46 \mathrm{~g} / \mathrm{kg}$ oil $\{=$ 
$28 \times(97.5+150) \div 150\}$, if the assumption is made that the SAMMS material was retained in the top layers of the solidified matrix. 
Appendix A

TREATMENT OF MERCURY CONTAMINATED ORGANICS

\title{
SAMPLING AND ANALYSIS PLAN
}

K. Thomas Klasson and Catherine H. Mattus

Oak Ridge National Laboratory ${ }^{1}$

Oak Ridge, Tennessee 37831-6226

\begin{abstract}
"The submitted manuscript has been authored by a contractor of the U.S. Government under contract No. DE-AC05-00OR22725. Accordingly, the U.S. Government retains a nonexclusive, royalty-free license to publish or reproduce the published form of this contribution, or allow others to do so, for U.S. Government purposes
\end{abstract}

\footnotetext{
${ }^{1}$ Managed by UT-Battelle, LLC, for the U.S. Department of Energy under contract DE-AC05-00OR22725
} 


\section{TREATMENT OF MERCURY CONTAMINATED ORGANICS SAMPLING AND ANALYSIS PLAN}

\section{PROJECT DESCRIPTION}

\subsection{Project Objectives}

The objective of sampling the solidified mixed oil waste is to determine the average concentration and variance of leachable mercury for each treatment method as well as determining if there is a stratified concentration of mercury in each container. The primary objective of the solidification studies was to demonstrate that High Mercury-Organic and Inorganic Subcategory liquid wastes can be treated using non-thermal processes to meet the concentration-based land disposal restriction (LDR) standard for Low Mercury Subcategory D009 nonwastewaters, which in this case is the Universal Treatment Standard (UTS). Data generated from these studies will be shared with EPA for potential support in the identification of an alternative BDAT for High Mercury-Organic and Inorganic Subcategory D009 wastes. The target treatment goal is to meet LDR/UTS limits for leachability $(0.025 \mathrm{mg} / \mathrm{L}$ for mercury) or at least the Resource Conservation Recovery Act limit $(0.2 \mathrm{mg} / \mathrm{L}$ for mercury).

\subsection{Background Information}

First Article Tests of a stabilization method for greater than $260 \mathrm{mg}$ mercury/kg oil were performed under a treatability study. This alternative treatment technology will address treatment of U.S. Department of Energy (DOE) organics (mainly used pump oil) contaminated with mercury and other heavy metals. Some of the oil is also co-contaminated with tritium, other radionuclides, and hazardous materials.

The technology is based on contacting the oil with a sorbent powder (Self-Assembled Mercaptan on Mesoporous Support, SAMMS), proven to adsorb heavy metals, followed by stabilization of the oil/powder mixture using a stabilization agent (Nochar N990). Two variations of the treatment technology were included in the treatability study.

The first approach involved dry-mixing of SAMMS material and Nochar N990 (4\% SAMMS by weight). This mixture was placed in a container (1 liter glass jar). The oil was then directly added to the container and allowed to be absorbed. Equal weight of oil and Nochar N990 was used.

The second approach involved mixing of SAMMS and oil for $24 \mathrm{hr}$. The amount of SAMMS used was $2 \%(\mathrm{w} / \mathrm{w})$. After mixing, the mixture was poured over Nochar 990 (in 1 liter glass jar). Equal weight of Nochar and oil was used.

\section{DETAILED COMPOSITION OF THE MATERIALS HANDLED}

\subsection{Discussion}

This section reports the process that was followed for the stabilization of the mixed waste oil sample.

\section{A-Bottles}

$150 \mathrm{~g}$ of Nochar N990 and $6 \mathrm{~g}$ SAMMS were dry-mixed in 1-L glass container for $1 \mathrm{~h}$. To this, $150 \mathrm{~g}$ of contaminated oil was added. The oil slowly penetrated the Nochar over time (approximately $30 \mathrm{~min}$ ). 


\section{B-Bottles}

$150 \mathrm{~g}$ of oil and $3 \mathrm{~g}$ of SAMMS were mixed in 1-L glass jars for $24 \mathrm{~h}$. This mixture was poured over 150 g Nochar N990 contained in a new 1-L glass jar. The oil slowly penetrated the Nochar over time (approximately $30 \mathrm{~min}$ ).

\subsection{Chemical Characteristics}

Based on the analytical data provided from Sandia National Laboratory the waste oil used in the stabilization contained $198 \mathrm{mg} / \mathrm{kg} \mathrm{Ba}, 6.5 \mathrm{mg} / \mathrm{kg} \mathrm{Cd}, 4 \mathrm{mg} / \mathrm{kg} \mathrm{Pb}, 0.5 \mathrm{mg} / \mathrm{kg} \mathrm{Ag}$, and $540 \mathrm{mg} / \mathrm{kg} \mathrm{Hg}$.

\subsection{Radiological Characteristics}

Based on the analytical data provided from Sandia National Laboratory, the waste oil used in the stabilization contained $12.8 \mu \mathrm{Ci}$ tritium contained in an estimated $755 \mathrm{~mL}$. When the oil arrived to ORNL it was determined that there was $900 \mathrm{~g}$ oil (approx. $1 \mathrm{~L}$ ). Thus, the corrected value for the radioactive component is $17 \mu \mathrm{Ci}$ in $900 \mathrm{~g}$ or $2.8 \mu \mathrm{Ci}$ per container of stabilized oil.

\section{ORGANIZATION AND RESPONSIBILITIES}

\subsection{Technical Lead Responsibilities}

K. Thomas Klasson will be responsible for sampling of the stabilized oil and transferring the samples according to the procedure outlined in this Sampling and Analysis Plan. Any deviation from the plan will be entered in a registered laboratory notebook. Klasson is responsible for record keeping and reporting results to DOE.

\subsection{Sampling Responsibilities}

K. Thomas Klasson will be responsible for sampling of the stabilized oil. Catherine H. Mattus will be responsible for the analysis as outlined in this Sampling and Analysis Plan. Any deviation from the plan will be entered in laboratory notebook. Mattus will transfer the results of the analyses to Klasson

\subsection{Analytical Laboratory}

The samples will be prepared and analyzed at ORNL within the Nuclear Science and Technology Division. Catherine H. Mattus will be responsible for the analysis. The mercury analyses will be performed using a Lehman PS 200 cold vapor atomic absorption spectrophotometer, the metals analyses using a Thermo Jarrell Ash $61 \mathrm{E}$ Trace inductively coupled plasma atomic emission spectrophotometer.

\section{DESCRIPTION OF SAMPLING PROCEDURE}

\subsection{Rationale for the Sampling Locations}

The A Bottles contained a well mixed quantity of SAMMS and Nochar N990 agents that received the mercury contaminated oil poured on top of the bed in the jar. This methodology could be generating a gradient of mercury concentration in the solids. Therefore, to verify this possibility, a stratified sampling will be used. 
The dimensions of the jar are $8.7 \mathrm{~cm}$ ID and $14.6 \mathrm{~cm}$ tall. The oil penetrated approximately $6.5 \mathrm{~cm}$ of the mixture of agents that had a height of approximately $10 \mathrm{~cm}$. The penetration depth is not uniform, neither is the upper surface (Figure 1).

Four strata will be sampled from each jar, each equal to approximately $1.5 \mathrm{~cm}$ of the height of the material inside the jar. In each stratum, one sample per quadrant will be taken, for a total of four per stratum and 16 per jar.

The B Bottles contained Nochar N990 and received oil mixed with SAMMS. The Nochar stabilization agent may act as a filter and the mercury laden SAMMS material may be retained in the top layer of the Nochar agent, creating a high-mercury layer. The sampling procedure is the same for both sets (A and B) of bottles. There is visually no difference in appearance.

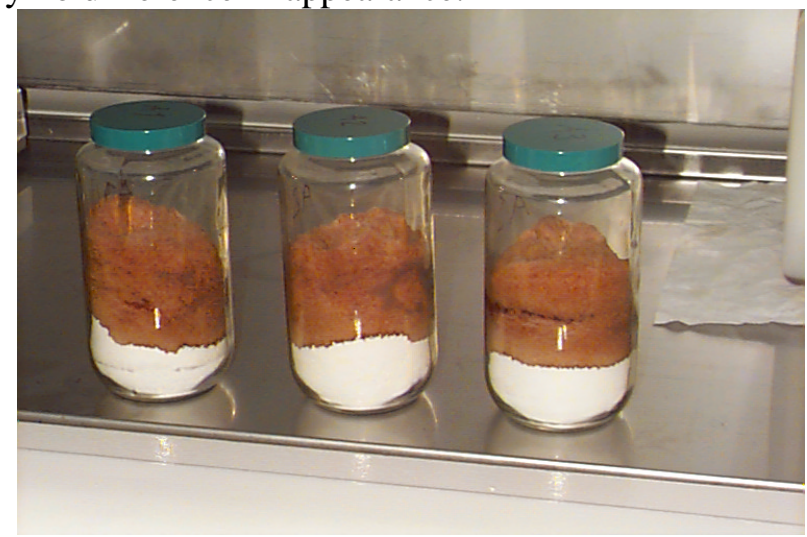

Figure 1. Stabilization of contaminated oil (A Bottles).

\subsection{Sampling Location}

The sample will be taken from the center of the quadrant and at the top of the stratum. An aliquot of $\sim 3$ grams will be removed from each quadrant using a plastic spoon and transferred into a precleaned bottle. After the four samples are removed, the remaining of the stratum will be transferred into a precleaned bottle. Then the top of the second stratum will be uncovered and ready for the same sampling. This operation will be done four times until the jar is empty or the average penetration depth is reached. Three of the 3-gram samples will be analyzed for total mercury. The forth 3-gram sample will be saved for future use. For each bottle, 4 samples (one from each stratum) will be collected for TCLP testing (mercury and other metals).

\subsection{Sample Designation}

Each sample bottle should be labeled at the time of collection. The labeling should contain the following information:

- bottle identification,

- unique sample number,

- date and time of collection, and

- the empty weight of the bottle including lid and label.

The unique sample number will appear in the following format:

A\# - S\#Q\#-DD - MM, 


\section{Appendix A}

where

A\# = solidified oil bottle number (e.g., A1);

$\mathrm{S \# Q \#} \mathrm{=} \mathrm{stratum} \mathrm{number} \mathrm{and} \mathrm{quadrant} \mathrm{number} \mathrm{(e.g.,} \mathrm{S1Q2} \mathrm{=} \mathrm{stratum} \mathrm{\# 1} \mathrm{and} \mathrm{quadrant} \mathrm{\# 2)}$

$\mathrm{DD} \quad=$ day of sampling;

$\mathrm{MM} \quad=$ month of sampling.

Labels should be affixed to the sample containers prior to or at the time of collection and should be filled out at the time of collection.

\section{SAMPLING LOGISTICS}

\subsection{Sample Selection}

The stabilization process used in the A Bottles was performed in triplicate, while the stabilization process for the B Bottles was performed in duplicate. Each bottle will be sampled as described in Section 4.

\subsection{Radiation and Contamination Exposure}

In order to reduce radiation exposure to personnel, the work shall be performed in accordance with the principle of ALARA (As Low As Reasonably Achievable). Radiation exposure may be controlled by reducing time spent in the area, maximizing distance between the source and the individual, and by providing shielding. The work is covered by a Radiation Work Permit (RWP) and conducted into a hood.

\subsection{Sample Collection}

Considering the small amount of sample in each jar, the sampling will be performed using disposable plastic spoons.

\section{SAMPLING EQUIPMENT AND PROCEDURES}

\subsection{Health and Safety Considerations}

The sampling operation must be performed by a person having completed Radiological Worker II training. The tasks should only be performed under conditions considered permissible by a RWP.

\subsection{Logbook Entries}

A logbook will be maintained to document all the sampling steps. All events should be recorded and should include, at a minimum, the following:

- date and time of sampling;

- name(s) of person(s) performing the sampling;

- list of samples collected, with the quantity of sample in each case;

- photograph and/or description of the jar's content;

- name given to the sample and recorded on the container(s) to be sent to the laboratory.

\subsection{Sample Collection}

Each of the bottles should have a label as described in Section 4. A summary of sample container, preservation, and holding time requirements is provided in Table 1. A sample tag, should be completed for each sample and affixed to the container. No sample preservative is to be used. After the sample has been transferred to a bottle, the bottle should be sealed and the weight should be noted. 
A blank sample of the stabilizing agents will be also taken for analysis.

Table 1. Requirements for samples

\begin{tabular}{|c|c|c|c|c|}
\hline $\begin{array}{l}\text { Analytical } \\
\text { parameter }\end{array}$ & Analytical methods & Sample container & Preservation & Holding time \\
\hline $\begin{array}{l}\text { TCLP analysis } \\
\text { (4 samples for each } \\
\text { bottle, one from } \\
\text { each stratum) }\end{array}$ & $\begin{array}{l}\text { SW846-1311,-6010B, } \\
-7470\end{array}$ & $\begin{array}{l}\text { 250-mL wide mouth } \\
\text { HDPE bottle }\end{array}$ & None & $\begin{array}{l}\text { Mercury } 28 \\
\text { days; other } \\
\text { metals } 180 \text { days } \\
\text { after extraction }\end{array}$ \\
\hline $\begin{array}{l}\text { Total Mercury } \\
\text { (12 samples from } \\
\text { each bottle, three } \\
\text { per stratum) }\end{array}$ & SW846-6010B, -7471 & $\begin{array}{l}\text { 60-mL wide-mouth } \\
\text { HDPE bottle }\end{array}$ & None & 28 days \\
\hline
\end{tabular}

Prior to their removal from the sampling area, the bottles need to be checked by health physicists to ensure that no outside contamination is present. The documentation for the chain of custody should then be filled out, and the samples should be prepared for transfer to the analytical laboratory.

\subsection{Decontamination of Sampling Equipment}

In order to prevent cross contamination of samples, a new disposable sampling tool will be used to retrieve samples from each stratum.

\section{SAMPLE HANDLING}

\subsection{Chain of Custody}

The possession and handling of each sample should be traceable from the time of collection until final disposition of the sample. This documentation of the history of the sample, called "chain of custody," has the following components: sample seals, field logbook, chain-of-custody record, and a form requesting sample analysis.

The chain-of-custody form should include the following, at a minimum:

1. sample number,

2. signature of collector,

3. date and time of collection,

4. place and location of collection,

5. waste type,

6. signature of persons involved in the chain of possession, and

7. inclusive dates of possession.

\subsection{Packaging and Shipping}

The samples should be delivered to the laboratory for analysis as soon as practicable. The samples need to be accompanied by the chain-of-custody record and by a form requesting sample analysis. The samples must be delivered to the person in the laboratory authorized to receive samples. Since the analytical laboratory is located in the same building as the laboratory where the experiment was conducted, there is no need for shipping. 


\section{Appendix A}

\section{ANALYTICAL NEEDS}

To verify the ability of the material to fix the mercury contaminated oil and the method for preparing the chemical agents, the total mercury concentration needs to be measured in all the strata sampled. For each stratum, triplicate samples were collected, each one from a different quadrant. The data generated will be treated by statistical method for:

- average mercury concentration in each stratum;

- existence of a gradient of concentration from top to bottom;

- reproducibility when comparing different jars using the same methodology.

Then, to verify that the treated material is stabilizing the mercury, a modified TCLP extraction will be performed on each stratum. The modification made from SW846-1311 method is a decrease in the quantity of material tested since the available total amount is limited. It is anticipated that $\sim 12$ to 15 grams of material would be tested with a 20 fold dilution using the appropriate extraction fluid. The concentration of other metals in the TCLP leachate will also be determined.

\section{ANALYTICAL REQUIREMENTS AND METHODOLOGY}

All the methods used will be following EPA methods from SW846. The total mercury analysis will be performed using a cold vapor atomic absorption (CVAA) instrument and following method 7471. The TCLP extraction will be a modified method 1311 (see Section 8). The ICP analysis on the TCLP leachate will use an inductively coupled plasma atomic emission spectroscopy (ICP-AES) instrument and follow method 6010B, with no sample digestion prior to the analysis. The mercury analyses on the TCLP leachate will be using cold vapor atomic absorption (CVAA) instrument and following method 7470.

\section{QUALITY ASSURANCE REQUIREMENTS}

The quality assurance/quality control requirements of SW846 methods should be met. Exceptions should be flagged in the data delivery report, and the laboratory should provide explanations regarding the nature of the deviations, as well as the corrective actions attempted.

\section{DATA DELIVERABLES}

The data deliverables include both a hard copy and an electronic copy of the sample data results. An electronic copy of the raw data, including calculations, should also be provided.

\section{DATA REVIEW AND VALIDATION}

Data review will be performed at ORNL. Data validation is not anticipated to be performed.

\section{REFERENCES}

U.S. Environmental Protection Agency, Method SW846-7471A, Mercury in Solid or Semisolid Waste (Manual Cold-Vapor Technique). (Web site: http://www.epa.gov/epaoswer/hazwaste/test/7471a.pdf )

U.S. Environmental Protection Agency, Method SW846-7470, Mercury in Liquid Waste (Manual ColdVapor Technique). (Web site: http://www.epa.gov/epaoswer/hazwaste/test/7470a.pdf )

U.S. Environmental Protection Agency, Method SW846-6010B, Inductively Coupled Plasma - Atomic Emission Spectroscopy. (Web site: http://www.epa.gov/epaoswer/hazwaste/test/6010b.pdf ) 


\section{Appendix A}

U.S. Environmental Protection Agency, Method SW846-1311, Toxicity Characteristic Leaching Procedure. (Web site: http://www.epa.gov/epaoswer/hazwaste/test/1311.pdf )

U.S. Environmental Protection Agency, Chapter 9, Sampling Plan. (Web site: http://www.epa.gov/epaoswer/hazwaste/test/chap9.pdf ) 